\title{
Olfactory Nerve Neoplasm
}

National Cancer Institute

\section{Source}

National Cancer Institute. Olfactory Nerve Neoplasm. NCI Thesaurus. Code C5121.

Benign and malignant neoplasms which arise from or metastasize to the olfactory or first cranial nerve. Clinical features may include facial pain and impairments of taste or smell. 